\title{
ARTICLE
}

\section{Forced solar gazing-a common technique of torture?}

\author{
Tim Fetherston ${ }^{1}$
}

Received: 5 December 2019 / Accepted: 5 December 2019 / Published online: 27 February 2020

(c) The Author(s), under exclusive licence to The Royal College of Ophthalmologists 2020

\begin{abstract}
Background Forced solar gazing (FSG) appears to be more regularly employed as a method of torture in certain parts of the world than has previously been documented.

Subjects and methods This study is a retrospective analysis of a case set of 17 torture survivors subjected to FSG, who were seen by the UK Charity Freedom from Torture in the period 2009-2019.

Results All clients in our case set had experienced serious physical and sexual assaults, in addition to the FSG, as part of their mistreatment. All clients suffered with serious psychological conditions as a result of their torture, including depression and post-traumatic stress disorder (PTSD). These mental health conditions made ophthalmic assessment difficult, not simply because of the clients' associated anxiety, but also because of avoidant behaviour and dissociation which was manifested in the clinical setting. In the two clients who could be examined by an ophthalmologist, both had visible retinal changes and a degree of impairment of visual acuity.

Conclusion FSG appears to be a method of torture which is regularly employed, and in our case set is seen with other serious manifestations of mistreatment, both physical, psychological and sexual. Psychiatric comorbidities present challenges in the clinical assessment of these cases. Ophthalmic examination can carry a risk of re-traumatisation of individuals who have experienced FSG in a context of torture.
\end{abstract}

\section{Introduction}

Freedom from Torture is a UK charity, which, since its formation in 1985, has provided support for over 50,000 victims of torture who have fled to the UK and sought asylum [1]. In 2018, Freedom from Torture provided direct assistance to 852 torture survivors in the UK, including psychological therapy, social assistance and advice, and assistance with asylum claims, together with the provision of expert medicolegal reports, documenting the residual signs of torture, both physical and psychological. The organisation therefore has extensive experience in assessing the physical and mental health issues encountered in torture survivors.

Ophthalmologists do not generally expect to encounter victims of torture as patients in clinical practice, particularly

Tim Fetherston

TFETHERSTON@freedomfromtorture.org

1 Freedom from Torture, 111 Isledon Road, London N7 7JW, UK in the UK. However, in the client group of Freedom from torture, it appears that ophthalmic aspects of injuries inflicted during torture-in particular Forced solar gazing (FSG)—are not uncommon. This study reviews a particular case set of torture survivors who were subjected to FSG as an element of their mistreatment.

Typically, during the episodes of mistreatment, the subject(s) were taken from their detention cell and forced to kneel or lie on the ground in bright sunlight at midday, and stare directly at the sun for periods of half an hour or more. If they did not comply with these orders, they were beaten, kicked, shocked with electric batons or sprayed with noxious liquid. This mistreatment was usually repeated numerous times, on successive days.

\section{Materials and methods}

This study is based on the review of a case set of 17 torture survivors who were subjected to FSG since 2009. It should be noted that the 17 cases reviewed are not exhaustive of all cases for which Freedom from Torture has documented FSG in the time period 2009-2019, but are a case set selected on the basis of availability of documentation and 
consent from the clients for the use of their information for research purposes. Any client who had not given consent for their data to be used in research, or in whom the consent could not be confirmed, was excluded from this report. Thus the 17 cases may not, in fact, represent all FSG experiences of survivors of torture which we have encountered over the period. The Freedom from Torture Research and Ethics Committee considered and approved the use of this data for the purpose of this study.

The documentation, and in particular the medicolegal reports, of clients who had an ophthalmic dimension to their torture was reviewed to confirm the nature of the mistreatment inflicted, (both general and specifically ophthalmic), the geographical location of the detention and torture, the nature of the presentation to Freedom from Torture, residual symptoms and signs, and to identify enduring comorbidities, both physical and psychological.

\section{Results}

All but one of the 17 clients in our case set were tortured in the Democratic Republic of Congo. One person was tortured in Sudan. Seven were male and ten female. Most had suffered a wide variety of significant physical injuries causing skin scarring in addition to the FSG. In our case set, the mean interval between torture and the medicolegal examination was nearly 2 years. Serious sexual assault was a feature of all cases, and all 16 Congolese torture survivors had experienced rape. This high incidence of sexual torture in survivors from the DRC is in keeping with that described in several recent reports [2, 3]. All torture survivors in our case set were suffering from serious psychological comorbidities in association with their mistreatment, principally post-traumatic stress disorder (PTSD), depression and problems with memory recall (especially in relation to autobiographical memory of the mistreatment events) [4].

\section{Challenges in assessment of ophthalmic symptoms and signs}

Torture survivors are often examined years after the events, in the context of an asylum application, and since the clinical signs of solar retinopathy often resolve with time, there may be little residual abnormality to see in the retina clinically by then [5]. Specialist ophthalmic equipment and retinal imaging facilities are not available at Freedom from Torture centres. As such, clients with possible retinal damage are referred to their GP for further investigation and onward referral to ophthalmology.

In our case set of 17, two could be examined by an ophthalmologist in the Freedom from Torture centre during the course of the preparation of their medicolegal assessment. Both had retinal clinical signs, one in the form of confluent circular patches of retinal pigmentary disturbance, and one in the form of small, congruent parafoveal pale chorioretinal patches. Both had some impairment of visual acuity - in one of these cases, corrected VA is recorded as 6/36 (hesitantly) each eye, and in the other case, 6/9 (hesitantly) each eye. However, the examinations were remarkable in that the clients exhibited a number of clinical features which appeared to be triggered by the process of examination itself, including pronounced involuntary blepharospasm, and a withdrawal response to bright lights, with head retraction and clear manifestation of heightened anxiety. One client appeared to experience episodes of psychological dissociation during the clinical assessment. This made evaluation of the findings very difficult.

\section{Discussion}

The definition of torture in the manual of the UN Convention against Torture and Other Cruel, Inhuman or Degrading Treatment or Punishment entails the intentional infliction of severe pain or suffering, for such purposes as intimidation, punishment, or to obtain a confession, such infliction being undertaken by, or on behalf of, a public official [6]. Torture survivors may have been targeted for various reasons, including their political affiliation, ethnicity, gender or sexual orientation. Survivors' accounts are frequently harrowing, and however robust and experienced a clinician may be, it can be exceptionally challenging to listen to them [7]. A huge range of different methods exist to inflict human pain and suffering, some horrifying beyond imagination.

Torturers may attempt to conceal their acts, in order to avoid physical evidence [8], using techniques which leave little physical sign of the mistreatment, whilst maximising its profound psychological effects. FSG may be regarded as falling into such a category.

At Freedom from Torture, a team of volunteer doctors provide medicolegal reports for clients, principally in relation to their claims for asylum. All such doctors receive training in psychiatric assessment and diagnosis, particularly in relation to those conditions found in asylum seekers and victims of torture, in accordance with the Istanbul Protocol.

This study shares the difficulties of many retrospective case analyses, in that all the desired specific data has not been addressed or recorded in the documentation, and several additional factors affect assessment of the ophthalmic issues in this context-

- Most of the Freedom from Torture medicolegal reports had been prepared by non-ophthalmologists, 
in the context of a medicolegal assessment in relation to an asylum claim, and the eye-related elements of the torture in the history were often eclipsed by the physical, sexual and psychological elements-these are often the most disabling and dehumanising problems with which the torture survivors are coping. In addition, from a medicolegal point of view, the non-ophthalmic aspects (such as skin scarring and psychiatric diagnoses) may represent the principal part of the legal submission. Therefore, the eye-related issues may, perhaps surprisingly, have received less attention in the medicolegal assessments than would be desired.

- The usual clinical facilities such as ocular imaging, photography and assessment of visual function are not available.

- Ophthalmic clinical assessment in this particularly traumatised patient group presents a number of significant challenges, which makes accurate assessment of visual acuity, and fundoscopy, very difficult.

\section{Forced solar gazing}

Some weeks or months after a solar gazing event, vision often improves significantly, to normal levels [9], but OCT imaging may show persistent changes despite the apparent resolution of clinical signs [10].

Solar retinopathy has long been described in a wide variety of circumstances, including eclipse watching [9], religious rituals [11], sunbathers [12], military gunners [13], pilots, telescopic solar viewing, psychiatric disorders [14] and the use of hallucinogenic drugs [15]. While there appears to be just one reported case of FSG as a modality of torture in the medical literature [16], Freedom from Torture has encountered FSG as a method of torture for more than two decades [7, 17, 18].

Solar retinopathy is described after as little as a few minutes sun gazing [5], but there are two main mechanisms of cellular damage, thermal and photochemical, the latter being a more likely mechanism if the pupil is undilated [19]. Photochemical damage requires longer exposures to sunlight and the degree of retinal damage or destruction is less severe than with a purely thermal injury. Our client group typically described being forced to look at the sun for half an hour or more.

\section{Psychological symptoms and post-traumatic stress disorder (PTSD)}

PTSD is defined as "... a delayed and/or protracted response to a stressful event... of an exceptionally threatening or catastrophic nature". [20]. All clients in our case set were diagnosed with PTSD. Typical symptoms are listed in Box 1.

Fear of blindness was a prominent feature in all clients' symptomatology, as were non-specific ophthalmic symptoms such as blurring of vision, lacrimation and ocular irritation. Patients with PTSD are at risk of being retraumatised by physical and psychological examination, which can precipitate a vivid re-living of their torture experiences [21]. Clients with PTSD exhibit "avoidance" behaviour, in order to reduce the risk of flashbacks and intrusive memories, and this can entail a reluctance to volunteer information and to discuss the events surrounding their torture.

This type of avoidance behaviour was particularly evident in attempts to perform ophthalmic examination in those who had been subjected to FSG, with intense blepharospasm, lacrimation, head movements and a withdrawal response being common when examining the clients with bright lights. In more extreme forms of response, the inadvertent reminder to the client of his or her mistreatment may precipitate an episode of "dissociation", in which he or she may appear to become vacant and detached from their surroundings, and need to be re-orientated gently and patiently in time and place. This can be disconcerting for clinicians who are not familiar with the phenomenon, and are unprepared to deal with it. Clearly, it is important that all these manifestations of severe mental trauma are recognised and not simply labelled as poor compliance with examination. It is equally important that patients who exhibit such avoidance behaviour and in whom PTSD is suspected are referred to their GP for specialist assessment and treatment. If the potential for re-traumatisation is suspected, it is vital to minimise distress by limiting, or even discontinuing the clinical examination. Obviously, care should be taken that

Box 1 typical symptoms of PTSD

- Vivid re-living of the trauma in intrusive memories ("flashbacks") or dreams

- A sense of emotional blunting or "numbness"

- "Dissociation": unresponsiveness to surroundings, detachment from other people

- Anhedonia-an inability to experience pleasure or enjoyment

- Avoidance behaviour-avoidance of activities and circumstances reminiscent of the trauma

- More rarely, dramatic, acute bursts of fear, panic or aggression triggered by stimuli arousing a sudden recollection/re-enactment of the trauma 
the clinical encounter does not inadvertently exacerbate suffering [22].

\section{Summary}

Freedom from Torture's evidence demonstrates that FSG appears to be regularly inflicted in the context of torture, particularly in certain parts of the world. FSG, in our case series, was associated with other comorbidities, particularly serious mental health issues. As there may be few residual clinical ophthalmic signs of this form of torture when a period of time has elapsed, it may be necessary to undertake retinal imaging studies. The patient may appear to have difficulty complying with the clinical examination, which should be modified or discontinued if the he or she experiences signs of distress. This should be recognised as a feature of the patient's mental trauma, and ophthalmologists should ensure that the patient is receiving appropriate psychological assessment and support.

"The sun and death, neither can be gazed at without flinching". [23]

\section{Summary}

\section{What was known before}

- Solar gazing has long been described as a cause of retinal damage in a wide variety of circumstances.

- There appears to be one previous report of FSG occurring in the context of torture.

\section{What this study adds}

- FSG appears to be employed as a method of torture regularly, particularly in certain regions of the world.

- FSG in our case set was merely one part of a complex pattern of torture, involving physical and sexual abuse including rape.

- In our case set, every case suffered with serious psychological comorbidities, particularly depression and PTSD.

- Avoidance behaviour, characteristic of patients with PTSD, may make ophthalmic assessment, visual acuity assessment and retinal examination very difficult.

- Patients with PTSD may be reluctant to volunteer information about their mistreatment, as part of their avoidance behaviour, particularly those who have experienced sexual torture.

- Exposure to bright lights during an ophthalmic assessment carries the risk of re-traumatisation of a vulnerable patient with PTSD who has been subjected to FSG, and examination should be modified or discontinued if the patient shows signs of distress.

Acknowledgements The author wishes to thank Emily Wilbourn and Jo Pettitt of the Research, Policy and Advocacy department of Freedom from Torture, and the Library staff of Sunderland Royal Hospital, for their generous and invaluable help.

Funding The author received no funding for the research and their medicolegal work for Freedom from Torture is voluntary and unpaid.

Consent to Publish The individuals gave consent for their anonymised data to be used in research and publication.

\section{Compliance with ethical standards}

Conflict of interest The author is a voluntary Medicolegal Report Doctor for the Human Rights Charity "Freedom from Torture".

Publisher's note Springer Nature remains neutral with regard to jurisdictional claims in published maps and institutional affiliations.

\section{References}

1. Freedom From Torture, London, Annual Report. 2018. https://www.freedomfromtorture.org/what-we-do/how-we\%27rerun/funding-and-annual-reports. Accessed 27 July 2019.

2. UK Foreign \& Commonwealth Office. Corporate report. Democratic Republic of Congo-Country of Concern. London; 2015. https://www.gov.uk/government/publications/democraticrepublic-of-congo-country-of-concern/democratic-republic-ofcongo-country-of-concern. Accessed 27 July 2019.

3. Freedom from Torture. A tool to silence: torture to crush dissent in the Democratic Republic of Congo. London; 2018. https://www. freedomfromtorture.org/a_tool_to_silence_torture_to_crush_dissent_ in_the_democratic_republic_of_congo. Accessed 15 Feb 2019.

4. Brewin CR. The nature and significance of memory disturbance in PTSD. Ann Rev Clin Psychol. 2011;7:203-27.

5. Moran S, O'Donoghue E. 'Solar retinopathy secondary to sungazing'. BMJ Case Rep. 2013. https://doi.org/10.1136/bcr-2012008402. Accessed 2 Dec 2019.

6. Office of the High Commissioner for Human Rights. 'Convention against Torture'. Ratified. 1984. https://www.ohchr.org/en/ professionalinterest/pages/cat.aspx. Accessed 29 Aug 2019.

7. Freedom from Torture. A tool to silence: torture to crush dissent in the Democratic Republic of Congo. London; 2018. https://www. freedomfromtorture.org/a_tool_to_silence_torture_to_crush_dissent in_the_democratic_republic_of_congo. Accessed 15 Feb 2019.

8. United Nations. Istanbul protocol: manual on the effective investigation and documentation of torture. New York and Geneva; 2004. Paragraph 159. https://www.ohchr.org/Documents/ Publications/training8Rev1en.pdf. Accessed 27 July 2019.

9. Michaelides M, Rajendram R, Marshall J, Keightley S. Eclipse retinopathy. Eye. 2001;15:148-51.

10. Koinzer S, Treumer F, Elsner H, Roider J. Retinopathia solaris: Verlaufsbeobachtung mit optischer Kohärenztomografie (OCT) und Mikroperimetrie. Klinische Monatsblätter für Augenheilkd. 2007;224:862-66. 
11. Hope-Ross M, Travers S, Mooney D. Solar retinopathy following religious rituals. Br J Ophthalmol. 1988;72:931-4.

12. Yannuzzi LA, Yale LF, Slakter J, Krueger A. Solar retinopathy: a photobiologic and geophysical analysis. 1989. Retina. 2012;32 Suppl 1:28-43.

13. Rosen E. Solar retinitis. Br J Ophthalmol. 1948;32:23-34.

14. Ruiz-del-Río N, Moriche-Carretero M, Ortega-Canales I, Revilla-Amores R, Peralta-Calvo JM. Photic maculopathy and iris damage in a psychotic patient. Arch Soc Esp Oftalmol. 2006;81:165-68.

15. Firth AY. Class A drug abuse: an ophthalmologist's problem?'. Eye. 2005;19:609-10.

16. Polat J, Feinberg E, Crosby SS. 'Ocular manifestations of torture: solar retinopathy as a result of forced solar gazing'. Br J Ophthalmol. 2010;94:1406-7.

17. Freedom from Torture. Rape as Torture in the DRC. London; 2014. https://www.freedomfromtorture.org/sites/default/files/201904/Final\%20web\%20-\%20a4\%20-\%20optimised.pdf. Accessed 27 July 2019.
18. Medical Foundation for the Care of Victims of Torture, 1998, Zaire, A torture state. https://refugeeresearch.net/sw/rrn_node/za ire-a-torture-state/. Accessed 13 Sep 2019.

19. Van Norren D, Vos JJ. Light damage to the retina: an historical approach. Eye. 2016;30:169-72.

20. World Health Organization. The ICD-10 classification of mental and behavioural disorders. Geneva; 1994. (F43.1: Post Traumatic Stress Disorder).

21. United Nations. Istanbul protocol: manual on the effective investigation and documentation of torture. New York and Geneva; 2004. Paragraph 149. https://www.ohchr.org/Documents/ Publications/training8Rev1en.pdf. Accessed 27 July 2019.

22. United Nations. Istanbul protocol: manual on the effective investigation and documentation of torture. New York and Geneva; 2004. Paragraph 217. https://www.ohchr.org/Documents/ Publications/training8Rev1en.pdf. Accessed 27 July 2019.

23. De la Rochefoucauld: Maximes et reflexions morales. Paris; 1665. LXXXVIII [26]: "Le soleil ni la mort ne se peuvent regarder fixement". 